J. Clin. Chem. Clin. Biochem.

Vol. 25, 1987, pp. $351-355$

(C) 1987 Walter de Gruyter \& Co. Berlin - New York

\title{
Interlaboratory Survey of the Quality of Urinary Arsenic and Thallium Assays in the European Community
}

\author{
By R. A. de Zeeuw, J. P. Franke \\ Dept. of Analytical Chemistry and Toxicology, State University Groningen, The Netherlands and \\ D. Stamm
}

Max-Planck-Institut für Psychiatrie, München, Germany

(Received January 22, 1987)

Summary: The present investigations were performed to assess the feasibility of an international round robin on biological samples, to assess the overall performance of toxicological laboratories in the European Community (EC) and the applicability of analytical methods used. Twelve laboratories representing 10 member countries within the Community, which could be considered to be well qualified for this type of work, participated in this study. The set-up chosen was that of a so-called long-term interlaboratory survey. It appeared that quality assurance by an international round robin is feasible within the EC. The samples consisted of arsenic and thallium, both at a high and a low level and the results of the individual laboratories as well as interlaboratory data are reported. In general, a good overall performance was seen, and the methods used showed acceptable accuracy and precision.

\section{Introduction}

It is now generally realised that quality assurance is essential in all areas of bioanalysis such as clinical chemistry, drug monitoring and analytical toxicology, and that internal and external quality control programmes are of utmost importance. Unfortunately, however, quality assurance in analytical toxicology is still in its infancy, especially with regard to international programmes.

The aims of the present investigations, which were made possible by the support of the Community Bureau of References (BCR) and the Deutsche Forschungsgemeinschaft (DFG) were to assess:

a) the feasibility of carrying out a round robin on samples of biological origin within a group of countries (suitability of samples, transportation across borders, turn-around time);

b) the overall performance of a selected group of toxicological laboratories in different countries; c) the applicability of the methods used by the individual laboratories with regard to accuracy and precision.

The samples chosen for this study consisted of artificial urine, spiked with arsenic and thallium, each at a high and at a low concentration. The reasons for selecting these samples were:

- minimal changes of decomposition of the analyte and the matrix

- availability of well documented reference values for the respective concentrations present

- the analysis for arsenic and thallium in urine can be considered as routine tasks for laboratories engaged in analytical toxicology.

The 12 participating laboratories from 10 different countries within the EC could be considered to be well qualified for this type of work. The analytical 
results obtained by these laboratories demonstrate the level of reliability and comparability of analysis achievable under routine conditions.

The study was set up as a so-called long-term interlaboratory survey $(1,2)$ to determine in control specimens:

a) assigned values for use in internal accuracy control;

b) decision limits for use in short-term interlaboratory survey for external quality control.

The requirements for assigned value determinations are (3):

- at least 3 reference laboratories for each analytical method used

- at least 10 duplicate determinations per analyte per method on 10 different working days under routine conditions, in order to get a reliable criterion for the distribution

- results for each laboratory and method (1st and 2nd results separately), in order to establish frequency distribution and statistical parameters, namely mean, day-to-day standard deviation, standard deviation of the series and median.

Duplicate determinations are also required to establish whether carry-over occurs between the 1st and 2nd determinations, and to see whether a large inprecision - if present - is due to within-day or dayto-day variation.

\section{Materials and Methods}

\section{Participants}

The following laboratories and individuals participated in this survey:

- Hôpital Fernand Widal, R. Bourdon, Paris, France

- Dept. Toxicology, University of Louvain, P. Daenens, Leuven, Belgium

- Central Pharmacy, The Hague Hospitals, I. C. Dijkhuis, The Hague, The Netherlands

- Police Forensic Science Laboratories, Gard Headquaters, $J$. Donovan, Dublin, Ireland

- Laboratory for Clinical and Forensic Toxicology, University of Padua, S. D. Ferrara, Padua, Italy

- Department of Legal Medicine, University of Erlangen, $M$. Geldmacher-v. Mallinckrodt, Erlangen, Federal Republic of Germany

- Department of Forensic Chemistry, University of Aarhus, B. Kaempe, Aarhus, Denmark

- Department of Toxicology, University of Thessaloniki, $A$. Kovatsis, Thessaloniki, Greece
- Central Research Establishment, Home Office Forensic Science Service, A. C. Moffat, Aldermaston, United Kingdom

- National Laboratory of Health, $R$. Wennig, Luxembourg, Luxembourg

- Poisons Unit, New Cross Hospital, B. Widdop, London, United Kingdom

- Department of Toxicology, State University, R. A. de Zeeuw, Groningen, The Netherlands

The Computer evaluation of the results was done by D. Stamm, Department of Clinical Chemistry, Max Planck Institut für Psychiatrie, Munich, Federal Republic of Germany.

\section{Samples}

Samples of lyophilized artificial urine were used at two levels of spiking. They were produced by Behringwerke A. G., Marburg, FRG and contained $\mathrm{Na}^{+}, \mathrm{K}^{+}$and $\mathrm{Cl}-{ }^{-}$in physiological concentrations, albumin, yellow dye and other organic constituents, such as trichloroacetic acid and 5-aminolaevulinic acid. In addition to $\mathrm{As}$ and $\mathrm{Tl}$, the matrix also contained $\mathrm{Pb}, \mathrm{Cd}, \mathrm{Cr}$, $\mathrm{Cu}, \mathrm{Ni}, \mathrm{Hg}$ and $\mathrm{F}$.

The levels of spiking were reported to be as follows:

Arsenic: added as meta-arsenate Batch No. 483: $200 \mu \mathrm{g} / \mathrm{l}$ As Batch No. 484: $600 \mu \mathrm{g} / 1$ As

Thallium: added as thallium acetate Batch No. 483: $70 \mu \mathrm{g} / \mathrm{Tl}$ Batch No. 484: $500 \mu \mathrm{g} / \mathrm{l} \mathrm{Tl}$

\section{Reference standards}

The following calibration reference standards of arsenic and thallium were sent to the participating laboratories: Arsenic as di-arsenic-trioxide (Merck, FRG, lot No. 118) and thallium as a solution of $\mathrm{Tl}(\mathrm{I}), 1.00 \mathrm{~g} / \mathrm{l}$, prepared from thallium nitrate (Aldrich, Belgium, lot No. 20, 460-9). As thallium nitrate is hygroscopic, a solution was sent to the participants.

\section{Round robin protocol}

A set of data sheets according to Hansert \& Stamm (3) was sent to the participating laboratories for reporting the results, together with a set of introduction sheets. Each laboratory had to carry out duplicate determination on 10 successive working days for each analyte and each sample.

\section{Results and Discussion}

\section{Instructions}

The instructions were found to be adequate. The reported data on the data sheets and reported information on methodology, calibration, etc. raised little or no confusion. There were little or no reporting errors.

\section{Samples}

Samples were shipped from Marburg, FRG, by parcel post with a customs declaration that reference samples for medical purposes were involved. Samples 
arrived in general within 10 days except for Greece (21 days). Custom clearance caused no problem and samples did not show any detrimental effects upon arrival.

Samples were considered adequate. No problems were reported in the redissolution of the lyophilized material, nor in the further handling.

\section{Analytical results for arsenic}

Figures 1 and 2 show for the individual laboratories the overall performance expressed as mean values with $95 \%$ confidence intervals. As, for the moment, no "definitive method" exists for determination of the true arsenic value, the true values were determined in a long-term interlaboratory survey in Germany by atomic absorption spectrometry via hydride formation. This technique is considered to be the most suitable for estimation of the true values.

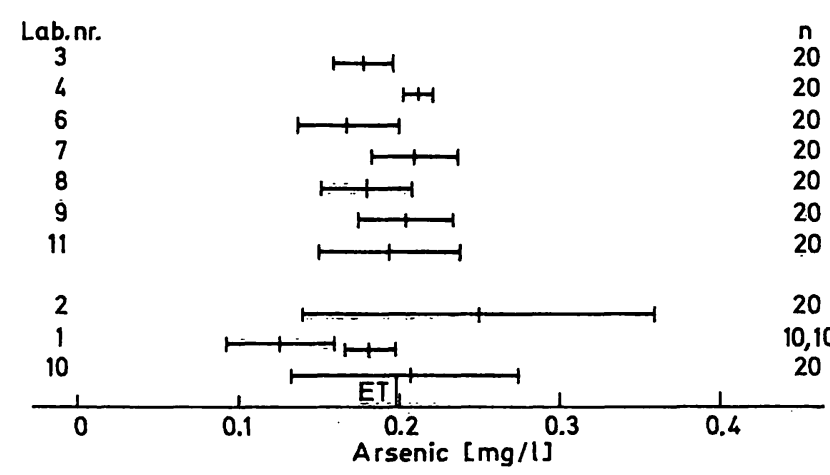

Fig. 1. Mean values and $95 \%$ confidence intervals for arsenic in urine, batch No. 483 .

Laboratories 3, 4, 6, 7, 8, 9, 11 Atomic absorption spectrometry with hydride formation

Laboratory 2 Gutzeit technique

Laboratories 1, 10 Spectrophotometry, hydride formation, silver diethyldithiocarbamate

ET indicates estimated true value.

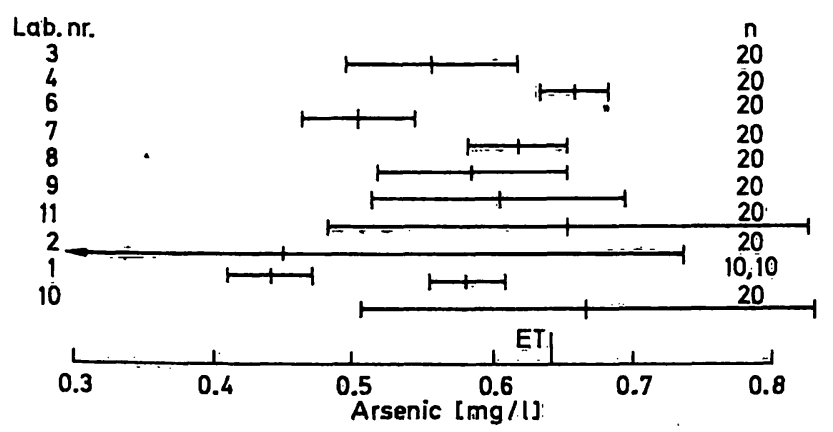

Fig. 2. Mean value and $95 \%$ confidence intervals for arsenic in urine, batch No. 484.

For further explanations see fig. 1.
Differences between the duplicate measurements were very small, indicating no carry-over between the first and second measurement. However, lab. 1 used 2 different ashing procedures for the duplicate measurements. It appeared that the ashing technique utilizing $\mathrm{Mg}\left(\mathrm{NO}_{3}\right)_{2}$ and $\mathrm{MgO}$, as recommended for As in meat, gave unsatisfactorily low yields when applied to urine samples. Therefore, with the exclusion of lab. 1, data from the individual laboratories were pooled.

Two labs were unable to provide data. The other labs were divided into two groups according to the techniques used:

1. atomic absorption spectrometry (AAS) via hydride formation (labs. 3, 4, 6, 7, 8, 9 and 11)

2. colorimetric determinations based on hydride formation, followed by colour reaction with silverdiethyldithiocarbamate (Ag-DDC), or on the Gutzeit technique (lab. 2).

For both groups interlaboratory statistical parameters are presented in table 1 . The results obtained by atomic absorption spectrometry lay close together and had good precision. The colorimetric determinations indicated that the Gutzeit technique - as expected - had a large scatter. The silver diethyldithiocarbamate technique provided better results, both with regard to accuracy and precision. If we compare the values obtained in this study with those obtained in Germany (tab. 1, estimated true values) it may be concluded that there is a good agreement. In addition, the precision values obtained in this study are quite acceptable.

\section{Analytical results for thallium}

The results of the individual laboratories expressed as mean values with 95 per cent confidence intervals are depicted in the figures 3 and 4 . For thallium isotope dilution mass spectrometry (IDMS) is the definitive method of choice for the moment. Results determined by Stoeppler (Jülich, FRG) are depicted in the figures 3 and 4 and shown in table 2.

The results for thallium were divided in 3 groups.

1. atomic absorption spectrometry with graphite furnace (GF) (labs. 3, 6, 7, 8, 11 and 12)

2. atomic absorption spectrometry with flame (labs. 5 and 9)

3. differential pulse anodic stripping voltametry (DPASV) (labs 1, 4 and 10). 
Tab. 1. Interlaboratory data and estimated true value of As concentration in control urine specimens (in $\mu \mathrm{g} / \mathrm{l}$ ).

\begin{tabular}{|c|c|c|c|c|c|c|}
\hline $\begin{array}{l}\text { Batch } \\
\text { No. }\end{array}$ & Analytical method & $\mathrm{m}$ & $\overline{\mathbf{x}}$ & $\overline{\mathrm{x}} \pm \overline{\mathrm{s}}$ & $\overline{\mathrm{CV}} \%$ & $\mathbf{k}$ \\
\hline \multirow[t]{2}{*}{483} & $\begin{array}{l}\text { Atomic absorption spectrometry } \\
\text { Photometry }{ }^{1} \text { ) }\end{array}$ & $\begin{array}{l}190 \\
208\end{array}$ & $\begin{array}{l}191 \\
218\end{array}$ & $\begin{array}{l}155-227 \\
149-287\end{array}$ & $\begin{array}{r}9.4 \\
15.9\end{array}$ & $\begin{array}{l}7 \\
3\end{array}$ \\
\hline & Estimated true value ${ }^{2}$ ) & & 199 & $186-212$ & $\cdot 1$ & \\
\hline \multirow[t]{2}{*}{484} & $\begin{array}{l}\text { Atomic absorption spectrometry } \\
\text { Photometry }{ }^{1} \text { ) }\end{array}$ & $\begin{array}{l}597 \\
590\end{array}$ & $\begin{array}{r}598 \\
\\
563\end{array}$ & $\begin{array}{l}493-702 \\
344-782\end{array}$ & $\begin{array}{r}8.8 \\
19.4\end{array}$ & $\begin{array}{l}7 \\
3\end{array}$ \\
\hline & Estimated true value ${ }^{2}$ ) & & 642 & $577-707$ & & \\
\hline
\end{tabular}

1) Two laboratories with 20 determinations each; one laboratory with 10 determinations.

$\left.{ }^{2}\right)$ Estimated true value, determined by atomic absorption spectrometry via hydride formation.

m: $\quad$ median;

$\overline{\bar{x}}, \overline{\mathrm{s}}$ and $\overline{\mathrm{CV}} \%$ : interlaboratory mean value, standard deviation and coefficient of variation, respectively;

$\mathrm{k}$ : number of laboratories.

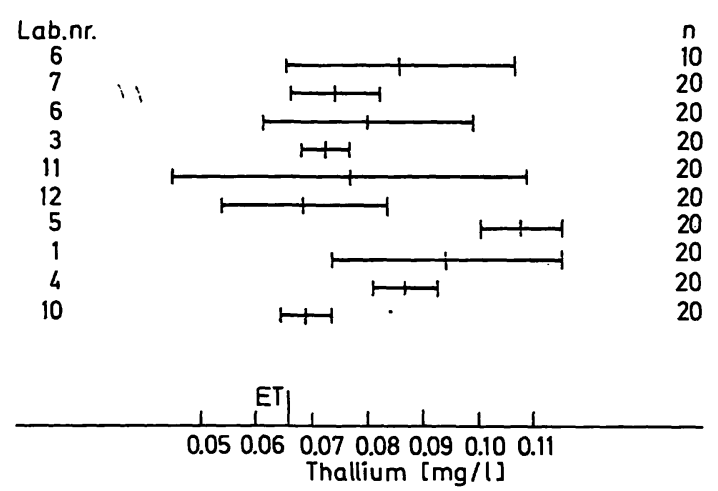

Fig. 3. Mean values and $95 \%$ confidence intervals for thallium in urine, batch No. 483 .

Laboratories 6, 7, 8 Atomic absorption spectrometry, graphite furnace, no extraction; laboratories $3,11,12$ same with extraction

Laboratories 5, 9 Atomic absorption spectrometry, flame, with extraction

Laboratories 1, 4, 10 Differential pulse anodic stripping voltametry

Laboratory 2 Spectrophotometry

ET indicates 'estimated true value'

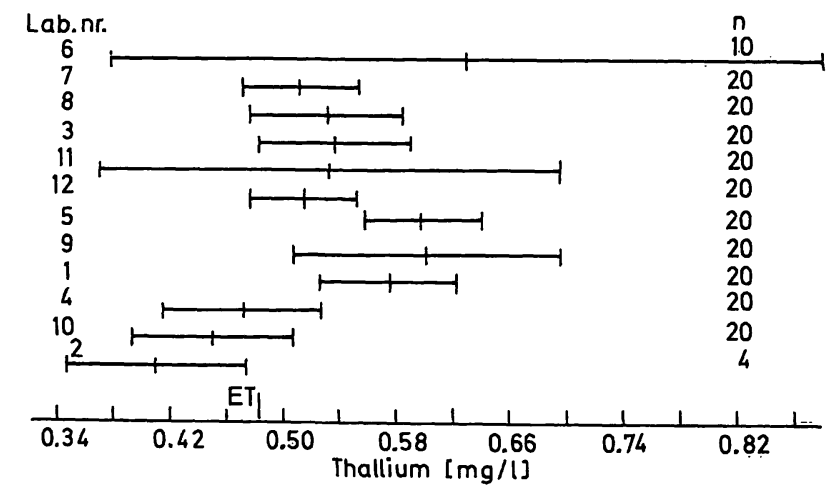

Fig. 4. Mean values and $95 \%$ confidence intervals for thallium in urine, batch No. 484.

For further explanations see fig. 3.
Lab. 9, using atomic absorption spectrometry with flame, was unable to measure $\mathrm{Tl}$ in the control urine at the low level (batch No. 483). Lab. 2 used a colorimetric procedure which appeared to be too insensitive for $\mathrm{Tl}$ in control urine 483, whereas for control urine 484 only two duplicate analyses could be performed.

The results obtained by atomic absorption spectrometry with graphite furnace as well as by differential pulse anodic stripping voltametry (tab. 2) showed good agreement and acceptable precision, although the interlaboratory coefficient of variation of differential pulse anodic stripping voltametry is nearly twice that of atomic absorption spectrometry with graphite furnace. Atomic absorption spectrometry with flame, using extraction of $\mathrm{Tl}$ from urine, gave yields that were too high, compared with the other techniques as well as with the estimated true value. The mean intralaboratory variability for atomic absorption spectrometry with graphite furnace is about $10 \%$ for both urine samples. Yet, with differential pulse anodic stripping voltametry, labs. 4 and 10 reported a higher variability in the sample with the high $\mathrm{Tl}$ level (484). When we compare the data for $\mathrm{Tl}$ found in this study with those of a recent interlaboratory survey on a national level in Germany, the mean interlaboratory values found in this study are somewhat higher (4).

\section{Conclusions}

- Quality assurance by means of "round robins appears feasible within the European Community

- The participating laboratories showed a good overall performance 
Tab. 2. Interlaboratory data and estimated true value of $\mathrm{Tl}$ concentration in control urine specimens (in $\mu \mathrm{g} / \mathrm{l}$ ).

\begin{tabular}{|c|c|c|c|c|c|c|}
\hline $\begin{array}{l}\text { Batch } \\
\text { No. }\end{array}$ & Analytical method & m & $\overline{\mathbf{x}}$ & $\overline{\mathrm{x}} \pm \overline{\mathrm{s}}$ & $\overline{\mathrm{CV}} \%$ & k \\
\hline \multirow[t]{5}{*}{483} & $\begin{array}{l}\text { Atomic absorption spectrometry } \\
\text { with graphite furnace }\end{array}$ & 73 & 76 & $64-88$ & 7.6 & 6 \\
\hline & $\begin{array}{l}\text { Atomic absorption spectrometry } \\
\text { with nlamed }\end{array}$ & 108 & 108 & $101-116$ & 3.1 & 1 \\
\hline & $\begin{array}{l}\text { Differential pulse anodic stripping } \\
\text { voltametry }\end{array}$ & 85 & 83 & $59-107$ & 14.4 & 3 \\
\hline & $\begin{array}{l}\text { Atomic absorption spectrometry }{ }^{2} \text { ) } \\
\text { Differential pulse anodic stripping } \\
\text { voltametry }{ }^{2} \text { ) }\end{array}$ & & $\begin{array}{l}70 \\
69\end{array}$ & $\begin{array}{l}45-95 \\
61-77\end{array}$ & & $\begin{array}{l}5 \\
3\end{array}$ \\
\hline & Estimated true value ${ }^{3}$ ) & & 66 & $59-73$ & 5 & 1 \\
\hline \multirow[t]{5}{*}{484} & $\begin{array}{l}\text { Atomic absorption spectrometry } \\
\text { with graphite furnace }\end{array}$ & 530 & 543 & $455-629$ & 7.9 & 6 \\
\hline & $\begin{array}{l}\text { Atomic absorption spectrometry } \\
\text { with flame }\end{array}$ & 600 & 600 & $531-669$ & 5.7 & 2 \\
\hline & $\begin{array}{l}\text { Differential pulse anodic stripping } \\
\text { voltametry }\end{array}$ & 402 & 499 & $379-620$ & 12.1 & 3 \\
\hline & $\begin{array}{l}\text { Atomic absorption spectrometry }{ }^{2} \text { ) } \\
\text { Differential pulse anodic stripping } \\
\text { voltametry }{ }^{2} \text { ) }\end{array}$ & & $\begin{array}{l}525 \\
475\end{array}$ & $\begin{array}{l}460-590 \\
440-510\end{array}$ & & $\begin{array}{l}5 \\
3\end{array}$ \\
\hline & Estimated true value & & 483 & $459-507$ & 5 & \\
\hline
\end{tabular}

1) $\bar{s}$ : intralaboratory day-to-day standard deviation

2) Assigned value and interval from Geldmacher-von Mallinckrodt et al. (4)

3) Estimated true value determined by Isotope-Dilution-Mass Spectrometry (fivefold assay)

m: median;

$\overline{\mathrm{x}}, \overline{\mathrm{s}}$ and $\overline{\mathrm{CV}} \%$ : interlaboratory mean value, standard deviak: tion and coefficient of variation, respectively; number of laboratories.

- In most cases, the methods used had acceptable accuracy and precision. Yet, atomic absorption spectrometry with flame appeared to give values that were too high in the analysis of thallium in urine.

It must be noted that the present study was an example of stable analytes in a relatively stable and simple matrix. It remains to be seen how the relatively long shipping times would affect samples that are more prone to degradation. Furthermore, in this study arsenic was added as meta-arsenate, whereas in actual

\section{References}

1. Stamm, D. (1982)

Long-term and short-term interlaboratory surveys within the framework of quality control in clinical laboratory investigations. In: IUPAC collaborative interlaboratory studies in chemical analysis (Egan, H. \& West, T. S., eds.) Pergamon Press, Oxford, New York, pp. 37-44.

2. Stamm, D. (1986)

Experience with quality control in clinical chemistry.

Z. Lebensm. Unters. Forsch. 182, 372-384. urine samples As can occur in different species (trivalent, pentavalent, organic As). Therefore, further studies ought to be attempted to include more complex matrices (blood plasma/serum, liquid natural urine) and/or more difficult analytes.

\section{Acknowledgement}

The Community Bureau of Reference (BCR) provided support for this study and for the evaluation of the results. The German Research Society (Deutsche Forschungsgemeinschaft) provided funds for obtaining the samples used in this study.
3. Hansert, E. \& Stamm, D. (1980)

Determination of assigned values in control specimens for internal accuracy control and for interlaboratory surveys. J. Clin. Chem. Clin. Biochem. 18, 461-490.

4. Geldmacher-von Mallinckrodt, M., Stamm, D. \& Enders, P. (1984)

Interlaboratory survey on thallium in urine.

Z. Rechtsmed. 93, 219-225.

\section{Dr. J. P. Franke}

Dept. of Anal. Chem. and Toxicology

Subfaculty of Pharmacy

State University

A. Deusinglaan 2

NL-9713 AW Groningen 
1 